OPEN ACCESS

Edited by:

Gabor Csanyi,

Augusta University, United States

Reviewed by:

Tohru Fukai,

Augusta University, United States

Patrick Pagano,

University of Pittsburgh, United States

*Correspondence:

Gábor Sirokmány

sirokmany.gabor@

med.semmelweis-univ.hu

Miklós Geiszt

geiszt.miklos@

med.semmelweis-univ.hu

Specialty section:

This article was submitted to

Inflammation,

a section of the journal

Frontiers in Immunology

Received: 08 October 2018

Accepted: 14 February 2019

Published: 05 March 2019

Citation:

Sirokmány G and Geiszt M (2019) The Relationship of NADPH Oxidases and Heme Peroxidases: Fallin' in and Out.

Front. Immunol. 10:394.

doi: 10.3389/fimmu.2019.00394

\section{The Relationship of NADPH Oxidases and Heme Peroxidases: Fallin' in and Out}

\author{
Gábor Sirokmány ${ }^{1,2 *}$ and Miklós Geiszt ${ }^{1,2 *}$ \\ ${ }^{1}$ Department of Physiology, Faculty of Medicine, Semmelweis University, Budapest, Hungary, ${ }^{2}$ "Momentum" Peroxidase \\ Enzyme Research Group of the Semmelweis University and the Hungarian Academy of Sciences, Budapest, Hungary
}

Peroxidase enzymes can oxidize a multitude of substrates in diverse biological processes. According to the latest phylogenetic analysis, there are four major heme peroxidase superfamilies. In this review, we focus on certain members of the cyclooxygenase-peroxidase superfamily (also labeled as animal heme peroxidases) and their connection to specific NADPH oxidase enzymes which provide $\mathrm{H}_{2} \mathrm{O}_{2}$ for the one- and two-electron oxidation of various peroxidase substrates. The family of NADPH oxidases is a group of enzymes dedicated to the production of superoxide and hydrogen peroxide. There is a handful of known and important physiological functions where one of the seven known human NADPH oxidases plays an essential role. In most of these functions NADPH oxidases provide $\mathrm{H}_{2} \mathrm{O}_{2}$ for specific heme peroxidases and the concerted action of the two enzymes is indispensable for the accomplishment of the biological function. We discuss human and other metazoan examples of such cooperation between oxidases and peroxidases and analyze the biological importance of their functional interaction. We also review those oxidases and peroxidases where this kind of partnership has not been identified yet.

Keywords: heme peroxidase, NADPH oxidase, hydrogen peroxide, reactive oxygen species, peroxidasin

\section{INTRODUCTION}

Heme peroxidases comprise a large number of heme-containing proteins. Families of these enzymes display distinct structural and biochemical properties and play a role in highly specialized biological processes. The numerous members of each of these families are expressed in all different kingdoms of life. Therefore, it had been recently suggested that the denomination of heme peroxidases should happen according to their characteristic enzymatic activities and structural properties instead of their animal, plant or fungal origin (1). The unique feature of the peroxidase-cyclooxygenase superfamily is the presence of a post-translationally modified heme group which is covalently linked to the peroxidase protein via two covalent bonds (2). Myeloperoxidase (MPO) is unique in this superfamily because of having three covalent linkages to the heme group. 
The activity of these peroxidases results in oxidation of oneelectron donors into the corresponding radical ( $\mathrm{AH}$ in Reaction 1) or oxidation of halides or pseudohalides (two-electron donors) into hypohalous acids (HOX in Reaction 2) (3).

$$
\begin{array}{r}
\text { Reaction }: \mathrm{H}_{2} \mathrm{O}_{2}+2 \mathrm{AH}_{2} \rightarrow 2 \mathrm{H}_{2} \mathrm{O}+2 \cdot \mathrm{AH} \\
\text { Reaction2: } \mathrm{H}_{2} \mathrm{O}_{2}+\mathrm{H}^{+}+\mathrm{X}^{-} \rightarrow \mathrm{H}_{2} \mathrm{O}+\mathrm{HOX}
\end{array}
$$

$\mathrm{H}_{2} \mathrm{O}_{2}$ is not only required for the generation of oxidants but it seems that it is also necessary to the autocatalytic activation of heme peroxidases during which process the heme-protein crosslink is reinforced (4).

Numerous biochemical processes can produce reactive oxygen species including hydrogen peroxide. The mitochondrial respiratory chain, several metabolic pathways, xanthine oxidase, monoamine oxidases, and the NADPH oxidases are all possible sources of $\mathrm{H}_{2} \mathrm{O}_{2}(5-7)$.

There are seven members of the Nox/Duox family of NADPH oxidases encoded in the human genome. In other species the number of NADPH oxidase homologs can vary greatly with only two isoforms present in Caenorhabditis elegans, five members in zebrafish, six in mouse and rat to name a few examples (8). The NADPH oxidases show important differences in tissue expression pattern and activation mechanism. Nox1, Nox2, Nox3, and Nox4 all require the membrane-bound $\mathrm{p} 22^{\text {phox }}$ protein to be able to produce ROS. Nox1, Nox2, and Nox3 also require different cytosolic factors to become active (9). However, Nox4 does not rely on cytosolic factors but is continuously active. Nox5, Duox1, and Duox 2 are independent of $\mathrm{p} 22^{\text {phox }}$ and are primarily activated by intracellular $\mathrm{Ca}^{++}$-signals. Interestingly, Duox proteins can be also classified as heme peroxidases although their peroxidase domain lacks a few critical amino acids that are required for the enzymatic activity of their $\mathrm{N}$-terminal peroxidase domain (10). Dual oxidase (Duox) proteins also require the activity of maturation factors DuoxA1 or DuoxA2 for proper folding and membrane targeting (11).

Hydrogen peroxide is not always the primary oxidant product of NADPH oxidases. Nox2 for example generates mainly superoxide anion, which can be further converted into $\mathrm{H}_{2} \mathrm{O}_{2}$ in a dismutation reaction enhanced by superoxide dismutase (SOD) enzymes (12). SOD catalyzes the disproportionation of the free radical superoxide anion resulting in the generation of molecular oxygen and hydrogen peroxide (see in Reaction 3) (13).

$$
\text { Reaction3 : } 2 \mathrm{O}_{2}^{-}+2 \mathrm{H}_{3} \mathrm{O}^{+} \rightarrow \mathrm{O}_{2}+\mathrm{H}_{2} \mathrm{O}_{2}+2 \mathrm{H}_{2} \mathrm{O}
$$

Certain members of the cyclooxygenase-peroxidase family rely specifically on hydrogen peroxide generated by an NADPHoxidase. In these specific cases, the absence of the corresponding NADPH-oxidase cannot be supplemented by any other $\mathrm{H}_{2} \mathrm{O}_{2}$ sources. This closely intertwined mode of action suggests evolutionarily conserved cooperation between these heme peroxidases and NADPH-oxidases. Our aim was to collect and analyze all known examples of such coactions.

The natural beauty of these peroxidase-oxidase concurrences is literally highlighted by a chemiluminescent light emitted during intense activation of the phagocyte myeloperoxidase or the fertilized sea urchin egg's ovoperoxidase $(14,15)$.

\section{LEUKOCYTE NOX2/MYELOPEROXIDASE SYSTEM}

The prodigious increase in oxygen consumption of phagocytosing leukocytes was already described in 1933 by C.W. Baldridge and R.W. Gerard (16). During the following decades, it became clear that this oxygen consumption was not dependent on mitochondrial respiration but was necessary for the production of reactive oxygen species by a complex, multi-protein system that comprised of membrane-bound and cytosolic factors. Nox2 (formerly known as gp91 ${ }^{\text {phox }}$ ) contains 6 transmembrane helices and forms a membrane-bound complex with $\mathrm{p} 22^{\text {phox }}$. Whereas, there are 4 cytosolic factors that in vivo are all necessary for a fully activated oxidase complex: p67 $7^{\text {phox }}, \mathrm{p} 47^{\text {phox }}, \mathrm{p} 40^{\text {phox }}$, and the small GTPase Rac1 or Rac2 $(9,17)$. These cytosolic components are all able to rapidly translocate to the gp91 ${ }^{\text {phox }}-\mathrm{p} 22^{\text {phox }}$ complex upon activation of the phagocyte. The gp91 $1^{\text {phox }}-\mathrm{p} 22^{\text {phox }}$ complex is stored in the peroxidase negative subsets of the neutrophil granulocytes' granules which-upon activation-fuse with the phagosomal or plasma membrane. Compared to other Nox isoforms, the ROS producing capacity of the activated Nox2 system seems to be extremely high $(18,19)$ and this might ensure the potent antimicrobial function of this isoform.

Another line of research elucidated the biochemical activity of myeloperoxidase that was present in large quantities (5\% of the total dry cell weight) in phagocytes and was able to turn $\mathrm{H}_{2} \mathrm{O}_{2}$ into microbicidal hypohalides like $\mathrm{HOCl}$ (20). Myeloperoxidase is stored mainly in the matrix of azurophilic granules of neutrophil granulocytes in a mature, dimeric form. The dimerization does not seem to affect the enzymatic activity of MPO but it is rather important for the stability and storage of the enzyme (21). In activated leukocytes, the granules can be released into the lumen of the forming phagosome or into the extracellular space around phagocytes $(22,23)$. The translocation of myeloperoxidase and Nox2 oxidase (cytochrome ${ }_{\mathrm{b} 558}$ complex of Nox 2 and $\mathrm{p} 22^{\mathrm{phox}}$ ) from cytoplasmic granules and vesicles into the phagosomal lumen was demonstrated by different approaches including studies based on subcellular fractionation, fluorescent and electronmicroscopic analysis (24-27).

The above regulatory mechanisms, multi-component assembly, and compartmentalization ensure that in nonstimulated cells there is practically no hypohalide production. This can prevent that aggressive antimicrobial reactive oxygen products cause random tissue destruction in the host.

Notably, human phagocytes express about an order of magnitude higher amounts of MPO than mouse leukocytes which limit the interpretation of mouse data. However, to circumvent this problem mouse models expressing human MPO have been established $(28,29)$. These models became important also to study the role of MPO in the pathomechanism of atherosclerotic lesion formation, as human atherosclerotic lesions do contain MPO and its peroxidation products whereas mouse MPO is hardly detectable in macrophages of atherosclerotic plaques. The expression of human MPO in mouse macrophages was unanimously associated with increased atherosclerotic lesions in different studies. However, other 
functional changes, like plasma lipoprotein and cholesterol levels showed more conflicting results, which might be explained by different transgenic systems used in different studies [i.e., bone marrow transplanted transgenic macrophages (28) or overall expression of the MPO transgene $(29,30)]$.

Similarly to the numerous other antimicrobial effector functions of phagocytes, dysregulation of superoxide production and myeloperoxidase activity can also contribute to the development of autoimmune diseases. Both the over activation or impairment of these processes can promote tissue damage associated with autoimmune conditions (31).

Furthermore, the lack of either Nox2 or MPO does result in immune deficiency disorder with substantially different characteristics and severity. In the absence of Nox2-or other components of the active phagocytic oxidase complex-a disease called chronic granulomatous disease (CGD) develops (32). CGD patients have largely increased susceptibility toward both bacterial and fungal infections. In contrast, many patients with loss of function mutations of MPO might have no obvious clinical symptoms or show an increased predisposition only toward fungal infections (caused mainly by Candida albicans) $(33,34)$. This phenotypic discrepancy might be explained in different ways. First, it is possible that the superoxide produced by Nox 2 and/or its derivatives exert direct antimicrobial effects even without being converted into hypochlorous acid. Second, based on observations showing altered membrane potential changes and $\mathrm{Ca}^{++}$-signals in CGD neutrophils it is possible to presume that altered intracellular ion concentrations might hamper also several other antimicrobial effector functions of these cells $(35,36)$.

\section{EOSINOPHIL NOX2/EOSINOPHIL PEROXIDASE SYSTEM}

Although the eosinophil peroxidase (EPO) and myeloperoxidase are highly homologous at the amino acid level their biochemical properties and biological role differ significantly. EPO binds its prosthetic group only via two covalent links and its spectral properties are more similar to that of LPO and TPO (2). Eosinophil granulocytes also express components of the Nox2 based superoxide-generating molecular machinery which provides $\mathrm{H}_{2} \mathrm{O}_{2}$ for EPO. Unlike MPO, EPO is not able to oxidize $\mathrm{Cl}^{-}$, but it uses mainly $\mathrm{Br}^{-}$and $\mathrm{SCN}^{-}$to generate hypobromous acid and hypothiocyanous acid, respectively. Detection of protein bromotyrosination can be used as a marker of EPO mediated protein oxidation (37).

Eosinophil granulocytes exert their antimicrobial and antiparasitic activities extracellularly and EPO is also a secreted protein. Eosinophils also play a special role in the pathologies of allergic inflammatory diseases (38-40). Despite the essential host defense and inflammatory role of eosinophil granulocytes the lack of eosinophil peroxidase activity does not manifest in any obvious phenotype in humans and the diagnosis of EPO deficiency is usually an accidental clinical finding (41). In contrast, in allergic diseases, accumulation and hyperactivity of eosinophil granulocytes are associated with overproduction of oxidative substances which contributes to the pathology of these conditions. An especially interesting pathomechanism is the activation of endothelium-derived tissue factor by hypothiocyanous acid with the consequentially increased risk of thrombotic complications $(42,43)$.

\section{DUOX2 AND THYROID PEROXIDASE IN THYROID HORMONE SYNTHESIS}

The thyroid peroxidase (TPO) catalyzes the iodination of tyrosine residues of thyroglobulin $(44,45)$. This peroxidase has got a unique transmembrane domain through which it is located in the apical membrane of thyrocytes. Its heme-containing catalytic site faces the thyroglobulin containing follicular lumen. To produce active iodine radicals the thyrocytes take up iodide ion through the basolateral $\mathrm{Na}^{+} / \mathrm{I}^{-}$symporter and transport it to the lumen through pendrin or through other apically located anion transporters (46). $\mathrm{H}_{2} \mathrm{O}_{2}$ is produced by dual oxidase 2 (Duox2), an other apically located transmembrane NADPH oxidase enzyme. The pharmacological inhibition or loss of function mutations of $\mathrm{I}^{-}$transporters, TPO or Duox2, and DuoxA2 all lead to insufficient thyroid hormone synthesisi.e., hypothyreosis.

As we have no detailed structural insight into the molecular vicinity of the luminal site of the thyrocyte, it is difficult to explain how the produced, highly reactive iodine radicals can react selectively with tyrosine side chains of thyroglobulin without eliciting oxidative damage of other extracellular proteins. Coimmunoprecipitation studies revealed a molecular interaction between TPO and Duox2 in the membrane fractions of isolated thyroid tissue lysates and of transfected COS-7 cells as well (47). This close association can at least explain how leakage of $\mathrm{H}_{2} \mathrm{O}_{2}$ can be prevented.

In contrast to the Nox2/MPO system, the thyroid hormone synthesis is a rather continuous, steady process. Accordingly, the oxidase and peroxidase components are located in the same subcellular compartment. Interestingly, the thyroid expresses two dual oxidases, Duox1 and Duox2 (48), but the absence of Duox1 is not associated with hypothyreosis (49). Therefore, the exact function of Duoxl in the thyroid is still unknown. It is also quite enigmatic why the highly homologous Duox1 cannot compensate for the lack of Duox2 in the hormone synthesis process. One explanation might be that Duoxl localizes to another microdomain of the apical membrane. However, the lack of Duoxl specific antibodies that work in immunohistochemistry applications makes it difficult to prove this idea (50).

\section{DUOX AND LACTOPEROXIDASE IN EXOCRINE GLANDS AND ON MUCOSAL SURFACES}

Lactoperoxidase (LPO) has long been recognized as an antimicrobial enzyme present in various exocrine secretions like milk, saliva, and tear. In 2003 a detailed in situ hybridization 
study identified Duox2 expression in major salivary ducts and on rectal epithelial cells and Duox1 expression in airway epithelial cells (58).

LPO can utilize $\mathrm{I}^{-}$or $\mathrm{SCN}^{-}$as substrates and the sodium/iodide transporter (NIS) plays an important role in transporting these anions through the epithelial cells. In the salivary glands LPO was expressed deep in the serous acini, NIS in the intercalated ducts and Duox2 in final ducts (58). This pattern of expression could ensure that the microbicide hypothiocyanous acid is formed only at later stages of secretion, just before entering the oral cavity.

In the airways, thiocyanate might be transported onto the epithelial surface via the cystic fibrosis transmembrane regulator CFTR (58-62). Decreased transport activity in cystic fibrosis patients might reduce the LPO mediated antimicrobial effects which might contribute to the high rate of pulmonary infections. Importantly microbes seem to be much more susceptible to HOSCN than mammalian cells probably because mammalian epithelial cells express high molecular weight thioredoxin reductase (TrxR) that can readily turn over HOSCN. In contrast, bacterial TrxR is strongly inhibited by HOSCN (62). This makes the Duox-LPO-HOSCN system much more adequate for continuous mucosal host defense functions than the more cytotoxic Nox2-MPO-HOCl system $(63,64)$.

\section{ELEGANS DUAL OXIDASE 1 (BLI-3) AND HEME PEROXIDASES}

The Caenorhabditis elegans NADPH oxidase, BLI-3 was described to be expressed in the hypodermal cells of C. elegans underlying the cuticle layer. The hypodermal cells play an essential role in the repeated synthesis of the cuticle (molting) during consecutive larval stages of the worm. RNAi knockdown of BLI-3 resulted in severe cuticle abnormalities. Di- and trityrosine crosslinks between cuticular collagen molecules were found to be significantly reduced in BLI-3 RNAi worms. The same study that described this phenotype also proposed that the BLI-3 peroxidase domain was responsible for the tyrosine crosslinks between cuticular collagens (65). However, later analysis revealed that the BLI-3 peroxidase domain lacks critical amino acids that are important for heme binding which makes its peroxidase activity doubtful. Accordingly, a reverse genetics RNAi screen approach identified the hypodermally expressed MLT-7 peroxidase that was responsible for collagen crosslinking (55). MLT-7 expression showed a cyclic pattern according to molting stages and its knockdown showed very similar phenotypes to BLI-3 knockdowns. It has been supposed that the enzymatically inactive BLI-3 peroxidase domain might function as a docking site for MLT-7 peroxidase domain thereby providing a spatial control of the peroxidase activity (55).

Another hypodermally localized heme peroxidase-SKPO1 -was also discovered by RNAi screening that was found to be important in maintaining normal cuticle phenotype. SKPO-1 was also claimed to play a role-along with BLI-3-in host defense against pathogenic bacteria $(56,66)$.

\section{OVOPEROXIDASE AND URCHIN DUAL OXIDASE 1 IN THE SEA URCHIN FERTILIZATION MEMBRANE}

In the sea urchin (Strongylocentrotus purpuratus) the fertilization of the egg elicits plasma membrane depolarization, cytosolic $\mathrm{Ca}^{++}$-signal and a cortical reaction which involves degranulation of vesicles located below the egg's membrane surface (67). This results in the formation of a stiff, insoluble fertilization envelope (FE) which prevents the entry of other sperms (53). The active pool of the sea urchin oxidase is located in the egg's plasma membrane whereas the ovoperoxidase is tethered to the forming FE by a protein called proteoliaisin $(54,68)$. Bennett M. Shapiro and his coworkers gave a detailed description of this envelope formation, they isolated and characterized the ovoperoxidase enzyme that is released from the granules and is responsible for the crosslinking of protein tyrosyl residues in this hardened membrane. Another important feature of the secreted peroxidase is its spermicidal activity which means an additional defense mechanism against polyspermy. Although the source of $\mathrm{H}_{2} \mathrm{O}_{2}$ for these peroxidase mediated reactions were already addressed in the 1977 PNAS paper, the molecular identification of the urchin dual oxidase (Udx1) was accomplished almost three decades later (54). This process is also a prime example of how compartmentalization and inducible translocation can ensure a swift, robust, but tightly controlled oxidative burst and peroxidase activation.

Although it is challenging to find quantitatively comparable data about the ROS production of different NADPH oxidase systems, it seems that the respiratory burst in the sea urchin egg results in a $\mathrm{H}_{2} \mathrm{O}_{2}$ concentration of about $60 \mathrm{nM}$ in the perivitelline space whereas in the phagosome of activated human neutrophil granulocytes the peroxide concentration is estimated to be in the micromolar range $(54,69)$. However, in the biological context of egg fertilization, this relatively lower rate of ROS production can still amply support the ovoperoxidase function.

\section{NOX5 AND HEME PEROXIDASE 2 IN MOSQUITO ANTIPLASMODIAL IMMUNITY}

A unique example has been identified in the midgut cells of Anopheles gambiae where the HPX2 heme peroxidase-in concert with Nox5 and nitric oxide synthase (NOS) - generates reactive nitrogen species (RNS) resulting in increased protein nitration. This process renders the Plasmodium ookinetes more susceptible to the Anopheles complement system which is the final effector mechanism against invading parasites (57) (see Table 1).

The same research group presented another mechanism in the Anopheles midgut where a Duox homolog cooperates with a secreted immunomodulatory epithelial peroxidase (IMPer) to form a dityrosine crosslinked matrix on the luminal surface. This matrix layer is supposed to separate the luminal microbiota and the epithelial immune system thereby subduing the immune activation and potential epithelial damage. On the other hand, Plasmodium parasites could proliferate more rapidly in the midgut lumen under these conditions (70). 
TABLE 1 | An overview of the peroxidase-oxidase co-operations discussed in detail in this paper.

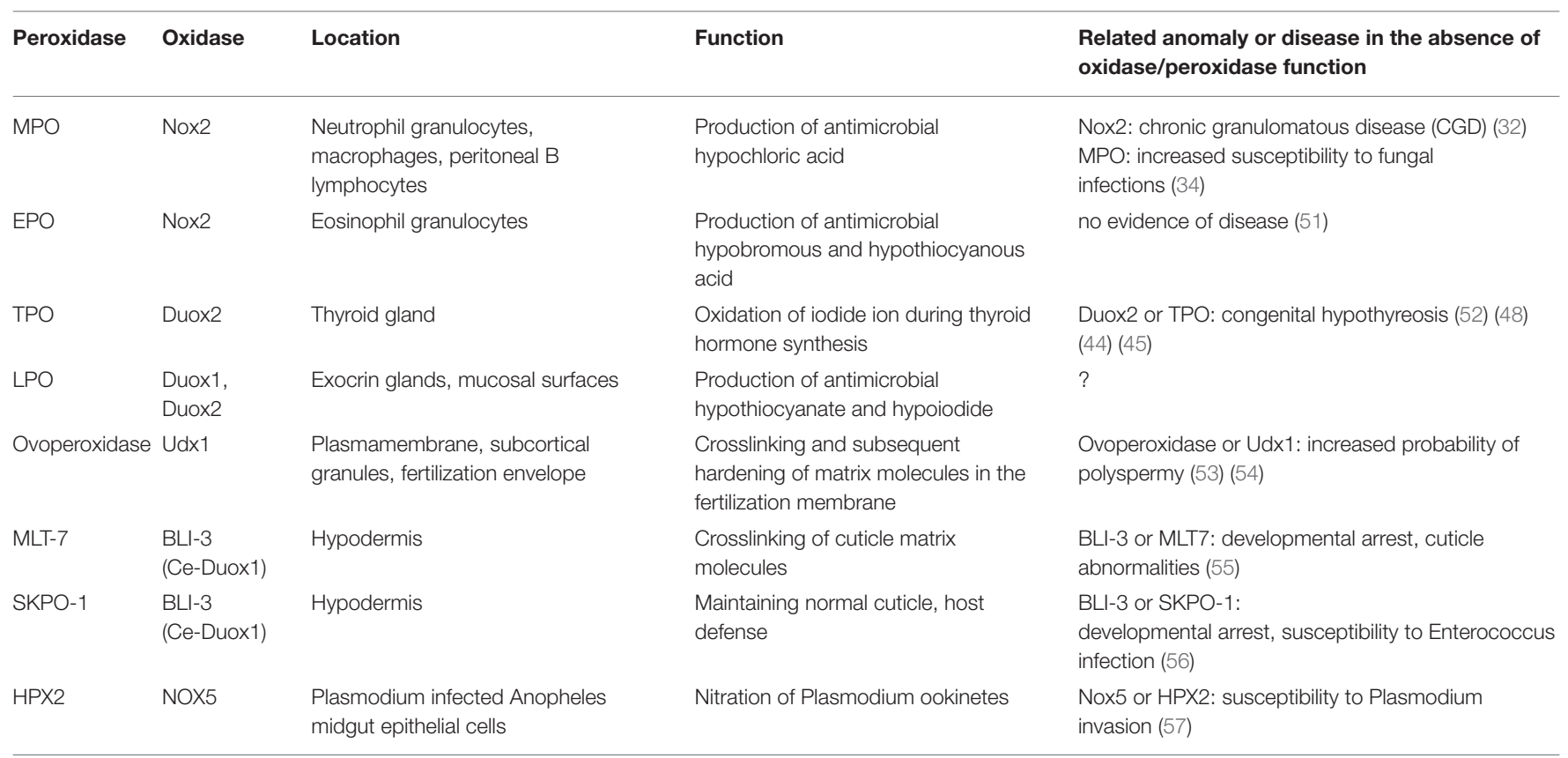

\section{NOX1, NOX3, AND NOX4 FUNCTION WITHOUT KNOWN PEROXIDASE PARTNERS}

These three members of the NADPH oxidase family have not been linked to heme peroxidases in any known biological process yet. Nox1 is mainly expressed in the distal parts of the gastrointestinal tract, showing low expression levels in the ileum, and more robust levels in the colon epithelium (19, 71). In a glutathione peroxidase deficient animal model of spontaneous ileocolitis, it was shown to be involved in the pathogenesis of inflammatory bowel diseases (72). This and other potential physiological functions of Nox1 are reviewed in detail elsewhere (73). However, cooperation with a known heme peroxidase has not been described in the divergent actions of Nox1.

Nox3 is uniquely expressed in the inner ear (74). Although there are no published data about any connection to heme peroxidases in this organ, it is interesting to note that-according to the publicly available NCBI Unigene database-myeloperoxidase has got a surprisingly high expression level in the mouse inner ear. Whether there is any functional link between MPO and Nox3 in the inner ear remains to be investigated.

The Nox4 expression is more ubiquitous with the highest levels found in the kidney. Uniquely this oxidase is constitutively active. The exact intracellular localization of Nox4 is still dubious, however many independent literature data points toward the endoplasmic reticulum where Nox4 might contribute to the oxidative milieu of the ER (75-77). It would be a challenging task to pinpoint any specific Nox4-heme peroxidase functional interaction within this compartment.

\section{PEROXIDASIN WITHOUT KNOWN OXIDASE PARTNER IN COLLAGEN IV CROSSLINKING}

Peroxidasin (Pxdn) has been described as the specific enzyme catalyzing the formation of sulfilimine covalent crosslink of Cterminal NC1 domains between collagen IV protomers (78). This unique, evolutionarily conserved chemical bond might significantly affect the mechanical and biochemical properties of collagen IV containing extracellular matrix structures. However, using various NADPH-oxidase deficient mouse models, it has been recently shown in vivo that NADPH oxidases most probably do not provide $\mathrm{H}_{2} \mathrm{O}_{2}$ for this reaction. P22 $2^{\text {phox }}$ mutant, Nox4 deficient, Duox1 knockout, and Duoxa double knockout animals were all equally capable to crosslink NC1 domains as wild-type control animals (79). Lysyl oxidases which are also involved in collagen IV assembly were also ruled out as possible ROS sources (78). Therefore, the exact molecular identity of this reactions' ROS source is still unknown. It is also a puzzling question how the Pxdn mediated reaction is restricted only to the collagen IV NC1 amino acids and how it is ensured that the highly reactive $\mathrm{HOBr}$ is not attacking numerous neighboring matrix molecules (80). Identification of a specific ROS source might help explain the spatiotemporal control of redox modification.

\section{CONCLUSION}

Our review describes the functional cooperation between members of the peroxidase-cyclooxygenase family and NADPH oxidases in various biological settings. The deeper understanding of these processes might help identify novel biological targets of 
oxidase and peroxidase products and improve our understanding of how these reactive oxidants can contribute to very specific, sophisticated physiological phenomena, or how they can trigger pathophysiological conditions.

\section{AUTHOR CONTRIBUTIONS}

All authors listed have made a substantial, direct and intellectual contribution to the work, and approved it for publication.

\section{REFERENCES}

1. Zamocky M, Jakopitsch C, Furtmüller PG, Dunand C, Obinger C. The peroxidase-cyclooxygenase superfamily: reconstructed evolution of critical enzymes of the innate immune system. Proteins Struct Funct Genet. (2008) 72:589-605. doi: 10.1002/prot.21950

2. Furtmüller PG, Zederbauer M, Jantschko W, Helm J, Bogner M, Jakopitsch $\mathrm{C}$, et al. Active site structure and catalytic mechanisms of human peroxidases. Arch Biochem Biophys. (2006) 445:199-213. doi: 10.1016/j.abb.2005.09.017

3. Zámocký M, Hofbauer S, Schaffner I, Gasselhuber B, Nicolussi A, Soudi M, et al. Independent evolution of four heme peroxidase superfamilies. Arch Biochem Biophys. (2015) 574:108-19. doi: 10.1016/j.abb.2014.12.025

4. Fayadat L, Niccoli-Sire P, Lanet J, Franc JL. Role of heme in intracellular trafficking of thyroperoxidase and involvement of $\mathrm{H} 2 \mathrm{O} 2$ generated at the apical surface of thyroid cells in autocatalytic covalent heme binding. J Biol Chem. (1999) 274:10533-8. doi: 10.1074/jbc.274.15.10533

5. Boveris A, Oshino $\mathrm{N}$, Chance B. The cellular production of hydrogen peroxide. Biochem J. (1972) 128:617-30. doi: 10.1042/bj1280617

6. Knowles PF, Gibson JF, Pick FM, Bray RC. Electron-spin-resonance evidence for enzymic reduction of oxygen to a free radical, the superoxide ion. Biochem J. (1969) 111:53-8. doi: 10.1042/bj1110053

7. Edmondson D. Hydrogen peroxide produced by mitochondrial monoamine oxidase catalysis: biological implications. Curr Pharm Des. (2014) 20:155-60. doi: 10.2174/13816128113190990406

8. Kawahara BT, Quinn MT, Lambeth JD. Molecular evolution of the reactive oxygen-generating NADPH oxidase (Nox/Duox) family of enzymes. BMC Evol Biol. (2007) 7:1-21. doi: 10.1186/1471-2148-7-109

9. Brandes RP, Weissmann N, Schroder K. Nox family NADPH oxidases: molecular mechanisms of activation. Free Radic Biol Med. (2014) 76C:208-26. doi: 10.1016/j.freeradbiomed.2014.07.046

10. Meitzler JL, Ortiz De Montellano PR. Caenorhabditis elegans and human dual oxidase 1 (DUOX1) "Peroxidase" domains: insights into heme binding and catalytic activity. J Biol Chem. (2009) 284:18634-43. doi: 10.1074/jbc.M109.013581

11. Grasberger H, Refetoff S. Identification of the maturation factor for dual oxidase. Evolution of an eukaryotic operon equivalent. J Biol Chem. (2006) 281:18269-72. doi: 10.1074/jbc.C600095200

12. Rister M, Baehner RL. The alteration of superoxide dismutase, catalase, glutathione peroxidase, and $\mathrm{NAD}(\mathrm{P}) \mathrm{H}$ cytochrome $\mathrm{C}$ reductase in guinea pig polymorphonuclear leukocytes and alveolar macrophages during hyperoxia. $J$ Clin Invest. (1976) 58:1174-84. doi: 10.1172/JCI108570

13. McCord JM, Fridovich I. Superoxide dismutase. An enzymic function for erythrocuprein (hemocuprein). J Biol Chem. (1969) 244:6049-55.

14. Foerder CA, Klebanoff SJ, Shapiro BM. Hydrogen peroxide production, chemiluminescence, and the respiratory burst of fertilization: interrelated events in early sea urchin development. Proc Natl Acad Sci USA. (1978) 75:3183-7. doi: 10.1073/pnas.75.7.3183

15. Allen RC, Stjernholm RL, Steele RH. Evidence for the generation of an electronic excitation state(s) in human polymorphonuclear leukocytes and its participation in bactericidal activity. Biochem Biophys Res Commun. (1972) 47:679-84. doi: 10.1016/0006-291X(72)90545-1

\section{FUNDING}

The research of the authors is supported by grants from the National Research, Development and Innovation Office (K119955, NVKP_16-1-2016-0039). The research was also financed by the Higher Education Institutional Excellence Programme of the Ministry of Human Capacities in Hungary, within the framework of the molecular biology thematic programme of the Semmelweis University. GS is a Bolyai fellowship holder of the Hungarian Academy of Science (BO/00504/18/5).

16. Gerard RW, Baldrige CW. The extra respiration of phagocytes. Am J Physiol. (1933) 103:235-6.

17. Sumimoto H, Miyano K, Takeya R. Molecular composition and regulation of the Nox family NAD(P)H oxidases. Biochem Biophys Res Commun. (2005) 338:677-86. doi: 10.1016/j.bbrc.2005.08.210

18. Björgvinsdóttir H, Zhen L, Dinauer MC. Cloning of murine gp91phox cDNA and functional expression in a human X-linked chronic granulomatous disease cell line. Blood. (1996) 87:2005-10.

19. Geiszt M, Lekstrom K, Brenner S, Hewitt SM, Dana R, Malech HL, et al. $\mathrm{NAD}(\mathrm{P}) \mathrm{H}$ oxidase 1 , a product of differentiated colon epithelial cells, can partially replace glycoprotein 91phox in the regulated production of superoxide by phagocytes. J Immunol. (2003) 171:299-306. doi: 10.4049/jimmunol.171.1.299

20. Klebanoff SJ, Clem WH, Luebke RG. The peroxidase-thiocyanatehydrogen peroxide antimicrobial system. BBA Gen Subj. (1966) 117:63-72. doi: 10.1016/0304-4165(66)90152-8

21. Banerjee S, Stampler J, Furtmüller PG, Obinger C. Conformational and thermal stability of mature dimeric human myeloperoxidase and a recombinant monomeric form from CHO cells. Biochim Biophys Acta. (2011) 1814:375-87. doi: 10.1016/j.bbapap.2010.09.015

22. Faurschou M, Borregaard N. Neutrophil granules and secretory vesicles in inflammation. Microbes Infect. (2003) 5:1317-27. doi: 10.1016/j.micinf.2003.09.008

23. Hansson M, Olsson I, Nauseef WM. Biosynthesis, processing, and sorting of human myeloperoxidase. (2006) 445:214-24. doi: 10.1016/j.abb.2005.08.009

24. Kjeldsen L, Sengeløv H, Lollike K, Nielsen MH, Borregaard N. Isolation and characterization of gelatinase granules from human neutrophils. Blood. (1994) 83:1640-9.

25. Casbon A-J, Allen L-AH, Dunn KW, Dinauer MC. Macrophage NADPH oxidase flavocytochrome $\mathrm{b}$ localizes to the plasma membrane and Rab11-positive recycling endosomes. J Immunol. (2009) 182:2325-39. doi: $10.4049 /$ jimmunol.0803476

26. Moriguchi K. Independent trafficking of flavocytochrome b558 and myeloperoxidase to phagosomes during phagocytosis visualised by energyfiltering and energy-dispersive spectroscopy-scanning transmission electron microscopy. J Microsc. (2018) 269:338-45. doi: 10.1111/jmi.12620

27. Jesaitis AJ, Buescher ES, Harrison D, Quinn MT, Parkos CA, Livesey S, et al. Ultrastructural localization of cytochrome $\mathrm{b}$ in the membranes of resting and phagocytosing human granulocytes. J Clin Invest. (1990) 85:821-35. doi: 10.1172/JCI114509

28. McMillen TS, Heinecke JW, LeBoeuf RC. Expression of human myeloperoxidase by macrophages promotes atherosclerosis in mice. Circulation. (2005) 111:2798-804. doi: 10.1161/CIRCULATIONAHA.104.516278

29. Castellani LW, Chang JJ, Wang X, Lusis AJ, Reynolds WF. Transgenic mice express human MPO -463G/A alleles at atherosclerotic lesions, developing hyperlipidemia and obesity in -463G males. J Lipid Res. (2006) 47:1366-77. doi: 10.1194/jlr.M600005-JLR200

30. Kumar AP, Piedrafita FJ, Reynolds WF. Peroxisome proliferatoractivated receptor $\gamma$ Ligands regulate myeloperoxidase expression in macrophages by an estrogen-dependent mechanism involving 
the-463GA promoter polymorphism. J Biol Chem. (2004) 279:8300-15. doi: $10.1074 /$ jbc.M311625200

31. Németh $\mathrm{T}$, Mócsai A, Lowell CA. Neutrophils in animal models of autoimmune disease. Semin Immunol. (2016) 28:174-86. doi: 10.1016/j.smim.2016.04.001

32. Baehner RL, Karnovsky ML. Deficiency of reduced nicotinamide-adenine dinucleotide oxidase in chronic granulomatous disease. Science. (1968) 162:1277-9. doi: 10.1126/science.162.3859.1277

33. Parry MF, Root RK, Metcalf JA, Delaney KK, Kaplow LS, Richar WJ. Myeloperoxidase deficiency. Prevalence and clinical significance. Ann Intern Med. (1981) 95:293-301. doi: 10.7326/0003-4819-95-3-293

34. Lehrer RI, Cline MJ. Leukocyte myeloperoxidase deficiency and disseminated candidiasis: the role of myeloperoxidase in resistance to Candida infection. $J$ Clin Invest. (1969) 48:1478-88. doi: 10.1172/JCI106114

35. Geiszt M, Kapus A, Német K, Farkas L, Ligeti E. Regulation of capacitative $\mathrm{Ca} 2+$ influx in human neutrophil granulocytes. Alterations in chronic granulomatous disease. J Biol Chem. (1997) 272:26471-8.

36. Geiszt M, Kapus A, Ligeti E. Chronic granulomatous disease: more than the lack of superoxide? J Leukoc Biol. (2001) 69:191-6. doi: 10.1189/jlb.69.2.191

37. $\mathrm{Wu} \mathrm{W}$, Chen Y, D'Avignon A, Hazen SL. 3-bromotyrosine and 3,5dibromotyrosine are major products of protein oxidation by eosinophil peroxidase: potential markers for eosinophii- dependent tissue injury in vivo. Biochemistry. (1999) 38:3538-48.

38. Ramirez GA, Yacoub M-R, Ripa M, Mannina D, Cariddi A, Saporiti N, et al. Eosinophils from physiology to disease: a comprehensive review. Biomed Res Int. (2018) 2018:9095275. doi: 10.1155/2018/9095275

39. Cottin V, Bel E, Bottero P, Dalhoff K, Humbert M, Lazor R, et al. Respiratory manifestations of eosinophilic granulomatosis with polyangiitis (ChurgStrauss). Eur Respir J. (2016) 48:1429-41. doi: 10.1183/13993003.00097-2016

40. Tashkin DP, Wechsler ME. Role of eosinophils in airway inflammation of chronic obstructive pulmonary disease. Int J Chron Obstruct Pulmon Dis. (2018) 13:335-49. doi: 10.2147/COPD.S152291

41. Kutter D, Janecki J, Verstraeten L. Screening for total and partial eosinoperoxidase deficiency by flow cytometry: prevalence in a general population, pathology and genetic implications. Redox Rep. (2000) 5:225-8. doi: $10.1179 / 135100000101535663$

42. Wu W, Samoszuk MK, Comhair SAA, Thomassen MJ, Farver CF, Dweik RA, et al. Eosinophils generate brominating oxidants in allergen-induced asthma. J Clin Invest. (2000) 105:1455-63. doi: 10.1172/JCI9702

43. Wang JG, Mahmud SA, Thompson JA, Geng JG, Key NS, Slungaard A. The principal eosinophil peroxidase product, HOSCN, is a uniquely potent phagocyte oxidant inducer of endothelial cell tissue factor activity: a potential mechanism for thrombosis in eosinophilic inflammatory states. Blood. (2006) 107:558-65. doi: 10.1182/blood-2005-05-2152

44. Magnusson RP, Chazenbalk GD, Gestautas J, Seto P, Filetti S, DeGroot LJ, et al. Molecular cloning of the complementary deoxyribonucleic acid for human thyroid peroxidase. Mol Endocrinol. (1987) 1:856-61. doi: 10.1210/mend-1-11-856

45. Kimura S, Kotani T, McBride OW, Umeki K, Hirai K, Nakayama T, et al. Human thyroid peroxidase: complete cDNA and protein sequence, chromosome mapping, and identification of two alternately spliced mRNAs. Proc Natl Acad Sci USA. (1987) 84:5555-9. doi: 10.1073/pnas.84.16.5555

46. Ravera S, Reyna-neyra A, Ferrandino G, Amzel LM, Carrasco N. The sodium/iodide symporter (NIS): molecular physiology and preclinical and clinical applications. Annu Rev Physiol. (2017) 79:261-89. doi: 10.1146/annurev-physiol-022516-034125

47. Song Y, Ruf J, Lothaire P, Dequanter D, Andry G, Willemse E, et al. Association of duoxes with thyroid peroxidase and its regulation in thyrocytes. J Clin Endocrinol Metab. (2010) 95:375-82. doi: 10.1210/jc.2009-1727

48. De Deken X, Wang D, Many MC, Costagliola S, Libert F, Vassart G, et al. Cloning of two human thyroid cDNAs encoding new members of the NADPH oxidase family. J Biol Chem. (2000) 275:23227-33. doi: 10.1074/jbc.M000916200

49. Donkó A, Ruisanchez E, Orient A, Enyedi B, Kapui R, Péterfi $\mathrm{Z}$, et al. Urothelial cells produce hydrogen peroxide through the activation of Duox1. Free Radic Biol Med. (2010) 49:2040-8. doi: 10.1016/j.freeradbiomed.2010.09.027
50. Caillou B, Dupuy C, Lacroix L, Nocera M, Talbot M, Ohayon R, et al. Expression of reduced nicotinamide adenine dinucleotide phosphate oxidase (ThoX, LNOX, Duox) genes and proteins in human thyroid tissues. J Clin Endocrinol Metab. (2001) 86:3351-8. doi: 10.1210/jc.86.7.3351

51. Zabucchi G, Soranzo MR, Menegazzi R, Vecchio M, Knowles A, Piccinini C, et al. Eosinophil peroxidase deficiency: morphological and immunocytochemical studies of the eosinophil-specific granules. Blood. (1992) 80:2903-10.

52. Niepomniszcze H, Castells S, De Groot LJ, Refetoff S, Kim OS, Rapoport $\mathrm{B}$, et al. Peroxidase defect in congenital goiter with complete organification block. J Clin Endocrinol Metab. (1973) 36:347-57. doi: 10.1210/jcem-36-2-347

53. Lafleur GJ, Horiuchi Y, Wessel GM. Sea urchin ovoperoxidase: oocytespecific member of a heme-dependent peroxidase superfamily that functions in the block to polyspermy. Mech Dev. (1998) 70:77-89. doi: 10.1016/S0925-4773(97)00178-0

54. Wong JL, Créton R, Wessel GM. The oxidative burst at fertilization is dependent upon activation of the dual oxidase udx1. Dev Cell. (2004) 7:80114. doi: 10.1016/j.devcel.2004.10.014

55. Thein MC, Winter AD, Stepek G, McCormack G, Stapleton G, Johnstone IL, et al. Combined extracellular matrix cross-linking activity of the peroxidase MLT-7 and the dual oxidase BLI-3 is critical for post-embryonic viability in Caenorhabditis elegans. J Biol Chem. (2009) 284:17549-63. doi: $10.1074 /$ jbc.M900831200

56. Tiller GR, Garsin DA. The SKPO-1 peroxidase functions in the hypodermis to protect Caenorhabditis elegans from bacterial infection. Genetics. (2014) 197:515-26. doi: 10.1534/genetics.113.160606

57. Oliveira GDA, Lieberman J, Barillas-Mury C. Epithelial nitration by a peroxidase/NOX5 system mediates mosquito antiplasmodial immunity. Science. (2012) 335:856-9. doi: 10.1126/science.120 9678

58. Geiszt M, Witta J, Baffi J, Lekstrom K, Leto TL. Dual oxidases represent novel hydrogen peroxide sources supporting mucosal surface host defense. FASEB J. (2003) 17:1502-4. doi: 10.1096/fj.02-1104fje

59. Fragoso MA, Fernandez V, Forteza R, Randell SH, Salathe M, Conner GE. Transcellular thiocyanate transport by human airway epithelia. J Physiol. (2004) 561(Pt. 1):183-94. doi: 10.1113/jphysiol.2004.071548

60. Lorentzen D, Durairaj L, Pezzulo AA, Nakano Y, Launspach J, Stoltz DA, et al. Concentration of the antibacterial precursor thiocyanate in cystic fibrosis airway secretions. Free Radic Biol Med. (2011) doi: 10.1016/j.freeradbiomed.2011.02.013

61. Moskwa P, Lorentzen D, Excoffon KJDA, Zabner J, McCray PB, Nauseef WM, et al. A novel host defense system of airways is defective in cystic fibrosis. Am J Respir Crit Care Med. (2007) 175:174-83. doi: 10.1164/rccm.200607-1029OC

62. Chandler JD, Nichols DP, Nick JA, Hondal RJ, Day BJ. Selective metabolism of hypothiocyanous acid by mammalian thioredoxin reductase promotes lung innate immunity and antioxidant defense. J Biol Chem. (2013) 288:18421-8. doi: 10.1074/jbc.M113.468090

63. Podrez EA, Abu-Soud HM, Hazen SL. Myeloperoxidase-generated oxidants and atherosclerosis. Free Radic Biol Med. (2000) 28:1717-25. doi: 10.1016/S0891-5849(00)00229-X

64. Ray RS, Katyal A. Myeloperoxidase: bridging the gap in neurodegeneration. Neurosci Biobehav Rev. (2016) 68:611-20. doi: 10.1016/j.neubiorev.2016.06.031

65. Edens WA, Sharling L, Cheng G, Shapira R, Kinkade JM, Lee T, et al. Tyrosine cross-linking of extracellular matrix is catalyzed by Duox, a multidomain oxidase/peroxidase with homology to the phagocyte oxidase subunit gp91phox. J Cell Biol. (2001) 154:879-92. doi: 10.1083/jcb.200103132

66. Chávez V, Mohri-Shiomi A, Garsin DA. Ce-Duox1/BLI-3 generates reactive oxygen species as a protective innate immune mechanism in Caenorhabditis elegans. Infect Immun. (2009) 77:4983-9. doi: 10.1128/IAI.00627-09

67. Veron M, Foerder C, Eddy EM, Shapiro BM. Sequential biochemical and morphological events during assembly of the fertilization membrane of the sea urchin. Cell. (1977) 10:321-8. doi: 10.1016/0092-8674(77)90226-4

68. Weidman PJ, Kay ES, Shapiro BM. Assembly of the sea urchin fertilization membrane: isolation of proteoliaisin, a calcium-dependent ovoperoxidase binding protein. J Cell Biol. (1985) 100:938-46. doi: 10.1083/jcb. 100.3.938 
69. Slauch JM. How does the oxidative burst of macrophages kill bacteria? Still an open question. Mol Microbiol. (2011) 80:580-3. doi: 10.1111/j.1365-2958.2011.07612.x

70. Kumar S, Molina-Cruz A, Gupta L, Rodrigues J, Barillas-Mury C. A peroxidase/dual oxidase system modulates midgut epithelial immunity in anopheles gambiae. Science. (2010) 327:1644-8. doi: 10.1126/science.1184008

71. Szanto I, Rubbia-Brandt L, Kiss P, Steger K, Banfi B, Kovari E, et al. Expression of NOX1, a superoxide-generating NADPH oxidase, in colon cancer and inflammatory bowel disease. J Pathol. (2005) 207:164-76. doi: 10.1002/path. 1824

72. Esworthy RS, Kim BW, Chow J, Shen B, Doroshow JH, Chu FF. Noxl causes ileocolitis in mice deficient in glutathione peroxidase-1 and-2. Free Radic Biol Med. (2014) 68:315-25. doi: 10.1016/j.freeradbiomed.2013.12.018

73. Sirokmány G, Donkó Á, Geiszt M. Nox/Duox family of NADPH oxidases: lessons from knockout mouse models. Trends Pharmacol Sci. (2016) 37:31827. doi: $10.1016 /$ j.tips.2016.01.006

74. Bánfi B, Malgrange B, Knisz J, Steger K, Dubois-Dauphin M, Krause KH. J Biol Chem. (2004) 279:46065-72. doi: 10.1074/jbc.M403046200

75. Prior KK, Wittig I, Leisegang MS, Groenendyk J, Weissmann N, Michalak $\mathrm{M}$, et al. The endoplasmic reticulum chaperone calnexin is a NADPH oxidase NOX4 interacting protein. J Biol Chem. (2016) 291:7045-59. doi: 10.1074/jbc.M115.710772

76. Zana M, Péterfi Z, Kovács HA, Tóth ZE, Enyedi B, Morel F, et al. Interaction between p22phoxand Nox4 in the endoplasmic reticulum suggests a unique mechanism of NADPH oxidase complex formation. Free Radic Biol Med. (2018) 116:41-9. doi: 10.1016/j.freeradbiomed.2017.12.031
77. Amanso AM, Debbas V, Laurindo FRM. Proteasome inhibition represses unfolded protein response and Nox4, sensitizing vascular cells to endoplasmic reticulum stress-induced death. PLoS ONE. (2011) 6:e14591. doi: 10.1371/journal.pone.0014591

78. Bhave G, Cummings CF, Vanacore RM, Kumagai-Cresse C, Ero-Tolliver IA, Rafi M, et al. Peroxidasin forms sulfilimine chemical bonds using hypohalous acids in tissue genesis. Nat Chem Biol. (2012) doi: 10.1038/nchembio. 1038

79. Sirokmány G, Kovács HA, Lázár E, Kónya K, Donkó Á, Enyedi B, et al. Peroxidasin-mediated crosslinking of collagen IV is independent of NADPH oxidases. Redox Biol. (2018) 16:314-21. doi: 10.1016/j.redox.2018.0 3.009.

80. Colon S, Page-McCaw P, Bhave G. Role of hypohalous acids in basement membrane homeostasis. Antioxid Redox Signal. (2017) 27:839-54. doi: $10.1089 /$ ars.2017.7245

Conflict of Interest Statement: The authors declare that the research was conducted in the absence of any commercial or financial relationships that could be construed as a potential conflict of interest.

Copyright (๑) 2019 Sirokmány and Geiszt. This is an open-access article distributed under the terms of the Creative Commons Attribution License (CC BY). The use, distribution or reproduction in other forums is permitted, provided the original author(s) and the copyright owner(s) are credited and that the original publication in this journal is cited, in accordance with accepted academic practice. No use, distribution or reproduction is permitted which does not comply with these terms. 